\title{
Expressionismo, epistemologia e política
}

\section{Romero Freitas, UFOP}

Resumo: O artigo procura mostrar como a seção "Barroco e expressionismo" do "Prefácio de crítica de conhecimento" contém mais do que uma comparação entre dois estilos artísticos. Ao falar sobre "o colapso da cultura classicista alemã", Benjamin pretenderia, na verdade, fazer um esboço das relações entre arte, política e ciência nos conturbados anos iniciais da República de Weimar.

Palavras-Chave: expressionismo; epistemologia; política.

Alle Straßen münden in schwarze Verwesung

Georg Trakl

A principal vanguarda alemã, o expressionismo, é assunto explicitamente discutido no prefácio de Origem do Trauerspiel alemão (1928). Qual seria o significado da comparação entre barroco e expressionismo que nós lemos aí? Uma leitura atenta dessa seção pode nos mostrar que, mais do que expressionismo e barroco, mais do que Kunstwollen e história da arte, o assunto dessa parte do livro é político: Benjamin discorre aí sobre a relação entre arte e violência naquilo que ele próprio denomina "o colapso da cultura classicista alemã". Porém, como em Benjamin quase nunca há política sem epistemologia (pois um dos seus principais temas é a crítica política da epistemologia), esse colapso do "classicismo" é também um sintoma de um acontecimento especificamente filosófico: o fim da filosofia como ciência sistemática.

A leitura dessa parte do "Prefácio de crítica do conhecimento" pode desfazer dois equívocos acerca da obra do jovem Benjamin. O primeiro, que já foi mais difundido, mas que tem ainda hoje alguns defensores, consiste em negar que a obra de juventude de Benjamin possua uma dimensão essencialmente política. Haveria, portanto, dois Benjamins: um místico, teológico, melancólico; outro marxista (ou anarquista), engajado na crítica do fascismo e da socialdemocracia. O segundo equívoco, que ainda tem certa força, pelo menos nos círculos filosóficos, consiste em negligenciar o conhecimento que Benjamin tem das manifestações literárias da época, isto é, suas leituras de Mallarmé, George, Hellingrath, Valéry (dentre outros) e seus contatos pessoais com Hofmannsthal, Hessel e Hugo Ball. Uma leitura atenta da seção "Barroco e expressionismo" poderá não apenas desfazer esses dois equívocos ${ }^{1}$ como mostrar que há um vínculo estreito entre expressionismo, epistemologia e política, e que esse vínculo é algo que perpassa o "Prefácio" como um todo.

Benjamin inicia a discussão sobre o expressionismo ${ }^{2}$ criticando a tendência dos contemporâneos a se identificarem com as obras do passado. A analogia entre o expressionismo e o barroco teria sido percebida, portanto, pelos próprios expressionistas, mas teria sido pensada pela via irrefletida da identificação. O procedimento da identificação gera uma perniciosa confusão entre as obras de arte 
concretas e o "fantasiar ensimesmado" 3 dos autores expressionistas. Benjamin acrescenta, porém, que as analogias entre o barroco e a arte atual podem produzir "uma compreensão que revele conexões autênticas, novas, não entre o crítico moderno e seu objeto, mas no interior do próprio objeto". ${ }^{4}$ Trata-se, portanto, menos de enfatizar o caráter arcaico ou medieval da arte, ao modo subjetivo dos expressionistas, do que de apontar o que a arte do presente revela, concretamente, sobre a arte anterior.

Uma análise formal da arte barroca revelaria, mais que qualquer hipótese sobre afinidades espirituais, uma analogia estilística entre o barroco e o expressionismo. Nos dois casos, busca-se um novo pathos. Mas o pathos (esse conceito tão tipicamente expressionista) está na linguagem, não na alma ou no espírito. Benjamin menciona, sobretudo, a criação de palavras novas:

A prática de fundir em um bloco o adjetivo, sem nenhuma função adverbial, com o substantivo, não é de hoje. 'Grandedança' [Großtanz], 'Grandepoema' [Großgedicht] (isto é, epopeia), são palavras barrocas. Neologismos, encontramos por toda parte. Hoje, como antes, em muitos deles o que se exprime é a procura de um novo pathos. Os poetas procuravam dominar pessoalmente a força mais íntima da imagem, a partir da qual emerge o preciso, mas delicado, poder metafórico da linguagem. Procurava-se a glória menos no discurso das parábolas do que nas palavras-parábolas, como se a criação da linguagem fosse a questão imediata da invenção poética das palavras. ${ }^{5}$

Benjamin exercita, nesse momento, o tipo de anacronismo consciente que é característico do seu método. O expressionismo é mobilizado em função de uma tarefa que o romantismo também desempenhará em várias partes do livro: mostrar que o barroco é contemporâneo da arte moderna, e que os procedimentos vanguardistas da colagem e da alegoria estão nele como nas peças de Werfel ou nos poemas de Benn. ${ }^{6}$

A principal questão, no entanto, é de natureza metafilosófica. A crítica da estética atemporal do classicismo, que predomina na universidade alemã da época, é também um meio de criticar o método analítico baseado na empatia, na identificação ou na revivência (Nacherleben). A hermenêutica neokantiana de Dilthey, bastante difundida no início do século, entende a filosofia como uma espécie de conhecimento empático ou compreensivo. Benjamin, no entanto, filia-se a uma tradição que remonta a Nietzsche, Marx e ao iluminismo: ele a concebe, essencialmente, como crítica (seja cultural, política, religiosa, estética, etc).

Benjamin pretende, portanto, superar o psicologismo tardo-romântico de alguns de seus contemporâneos, a começar por Wilhelm Dilthey. ${ }^{7}$ O que ele descobre nos expressionistas, que eram inimigos declarados do classicismo, é uma afinidade não percebida com a estética clássica. Nos dois casos - no pensamento acadêmico dos filólogos e na militância vanguardista dos poetas -, Benjamin identifica uma aliança perversa entre a atemporalidade clássica e o historicismo romântico. É por isso que Origem do Trauerspiel alemão é um livro duplo: ao mesmo tempo uma provocação da filologia germânica e uma crítica da arte de vanguarda expressionista. Ao mesmo tempo, Benjamin não se limita a uma provocação da filologia e a uma crítica da vanguarda. A dupla crítica serve de introdução a uma proposta filosófica nova. Benjamin apresenta no "Prefácio", como já se observou, ${ }^{8}$ uma reflexão original 
sobre o estatuto da escrita e do estilo na filosofia. O que talvez não se tenha observado é que há uma nítida vantagem em ler o "Prefácio" "de trás para frente". O fim do texto é que nos revela qual é de fato o inimigo principal: não o método da demonstração geométrica (pois que sentido haveria em criticar um método do século XVII - já abandonado pelo iluminismo, pelo naturalismo e pelo historicismo - no início do século XX?), mas o método da empatia, da identificação ou da revivência (amplamente difundido no pensamento acadêmico e na cultura artística da época). ${ }^{9}$

A metafilosofia de Benjamin propõe substituir a empatia pela leitura imanente. Mas essa leitura imanente não é tão simples como se pensa. Em relação ao formalismo do início do século XX, bastante presente no new criticism e na crítica "kantiana" de Clement Greenberg, a leitura benjaminiana apresenta pelo menos duas diferenças fundamentais: não rejeita a abordagem científica da obra de arte, nem proíbe de modo puro e simples toda forma de contextualização. Em relação à crítica contextualista do final do século XIX, o método de leitura de Benjamin inova num ponto fundamental: ele não lê a obra como um texto inserido em um contexto, mas, antes, lê o contexto como inserido na obra. Tomemos um exemplo bem simples: para Benjamin, o Trauerspiel diz mais sobre a Guerra dos 30 Anos do que a Guerra dos 30 Anos diz sobre o Trauerspiel. No segundo caso, temos a interpretação de Louis Wysocki, que Benjamin rejeita: a precariedade formal das peças se deveria à precariedade cultural do tempo, ao embrutecimento do público depois de uma prolongada guerra, etc. ${ }^{10}$ No outro caso, temos a hipótese de Benjamin: a forma aberta das peças, o seu caráter fragmentário, é expressão do modo como os autores veem (e vivem) a história: como deperecimento impiedoso de todas as coisas, sem telos sagrado (como no pensamento medieval) ou profano (como na filosofia da história dos séculos XVIII e XIX). ${ }^{11}$

Se falamos aqui de "metafilosofia", e não de "filologia", é porque Benjamin faz filosofia através da filologia. O conhecimento de um gênero literário específico (objetivo "exotérico" do livro) é também um meio para o reconhecimento de uma crise do presente (objetivo "esotérico" do livro). De qual crise de trata? Da crise ou colapso dos estudos clássicos na Alemanha, tal como Benjamin a interpreta na seção "Barroco e expressionismo". Essa crise dos estudos clássicos deve ser pensada como o início de uma mudança de paradigma. "Clássicos", em sentido amplo, são autores tão diversos como Winckelmann, Goethe, Schiller e Hegel. Mas, para Benjamin, o que há em comum entre esses autores, o que os opõem ao pensamento barroco, é uma tendência a pensar a história como uma totalidade ou sistema. A questão extrapola, portanto, o domínio da pura filologia. Ela diz respeito a um problema de epistemologia da história.

Vejamos, então, como funciona o método imanente de Benjamin e como ele nos fornece a chave para o significado metafilosófico do "Prefácio". Nossa hipótese de leitura será a seguinte: ao retirar o barroco do lugar onde ele estava, como forma precária e intermediária de dramaturgia, situada entre o drama aristotélico da Renascença e o drama burguês do século XVIII, Benjamin rompe também com a filosofia da história que é imanente a essa classificação dos gêneros literários. Dessa forma, podemos refletir de modo rigoroso sobre algo que muitas vezes ocorre na experiência de leitura: a impressão inquietante de que o livro é não apenas uma tese sobre o barroco, mas, em alguns momentos, parece ser também a defesa "esotérica" de uma concepção barroca da história. A crise de Weimar tem, portanto, uma afinidade eletiva com a crise barroca. E a inquietação principal, nas duas crises, é a mesma: Como pensar a história após a perda de uma orientação a priori para a ação 
no mundo, isto é, como pensar a ação depois do desaparecimento do telos histórico universal? A natureza desse telos, naturalmente, é distinta: enquanto na Republica de Weimar é a teleologia do progresso que parece fraquejar, no século XVII é a escatologia cristã que parece ausentar-se do horizonte da ação. Nos dois casos, no entanto, é evidente que se trata de uma crise da teleologia.

Voltemos, portanto, às afinidades eletivas entre o barroco e o expressionismo. Para criar uma aproximação entre essas duas formas de arte, Benjamin recomenda uma comparação do "interior" das obras entre si, isto é, uma comparação entre a linguagem das obras:

Sobretudo na dimensão da linguagem é evidente a analogia entre o esforço de outrora e o esforço do momento atual e do passado mais recente. O elemento forçado é característico de ambos. Ao mesmo tempo em que não crescem a partir da existência comunitária, as formas dessas literaturas procuram ocultar, através de um estilo violento, a falta de produtos válidos na literatura. Pois, como o expressionismo, o barroco é menos a era de um verdadeiro fazer artístico do que a era de um incorruptível querer artístico [Kunstwollen.$^{12}$

$\mathrm{Na}$ sequencia dessa passagem, Benjamin explica que esse predomínio do "querer artístico" (expressão tomada de empréstimo ao historiador da arte Alois Riegl) sobre a "realização artística" resulta em um privilégio da "forma enquanto tal" sobre "a obra individual bem realizada". ${ }^{13} \mathrm{Ou}$ seja: tanto no expressionismo quanto no barroco há um predomínio do ato de escrita, da experimentação em si, sobre o produto final. Mas essa escrita experimental não pode ser confundida com nenhum tipo de experimentalismo vazio ou puramente formal. Ela orienta-se para um objetivo bem definido, que poderíamos chamar de "mimético": "a busca por um estilo rústico de linguagem, que pareça colocá-la à altura do ímpeto do que acontece no mundo". ${ }^{14}$

Como se vê, Benjamin articula forma e política de modo bem explícito. A temática da "politização da arte" (resposta do comunismo ao fascismo, no ensaio sobre a reprodutibilidade técnica, escrito e rescrito entre 1935 e 1939) já está presente nessa seção, embora ela tenha aí a forma que o expressionismo lhe dá: uma espécie de sismógrafo do "estado das coisas" na década que vê o início e o fim da Primeira Guerra Mundial, a chamada "década expressionista". ${ }^{15}$ Um bom exemplo desse "estado das coisas" é o célebre poema programático de Jakob von Hoddis, significativamente intitulado "Fim do mundo":

O chapéu voa da cabeça do cidadão,

Em todos os ares retumba-se gritaria.

Caem os telhadores e se despedaçam

E nas costas - lê-se - sobe a maré.

A tempestade chegou, saltam à terra

Mares selvagens que esmagam largos diques.

A maioria das pessoas tem coriza.

Os trens precipitam-se das pontes. ${ }^{16}$ 
Benjamin propõe, ao mesmo tempo, uma leitura política e uma leitura imanente das obras literárias. Antecipando uma técnica de leitura que se tornaria célebre com Theodor Adorno, Benjamin desenvolve uma dialética entre autonomia e heteronomia da obra de arte: a heteronomia social se exprime na autonomia formal. A arte é experimental na medida em que, na sociedade, há pouco espaço para a experimentação política, cultural, pedagógica, etc. Esse é o seu elemento "mimético". O momento presente é caracterizado, de modo nítido, por duas coisas: pela marginalização ${ }^{17}$ do artista ("não crescem a partir da existência comunitária") e pela precariedade formal da sua produção ("falta de produtos válidos"). As duas coisas se reúnem numa espécie de "violência estilística". A arte torna-se então menos "arte", no sentido clássico do termo ("aparência sensível da ideia" ${ }^{18}$ ), do que testemunho, expressão ou sintoma. Nos termos de Benjamin: a arte "à altura do ímpeto do que acontece no mundo" é aquela nascida do "colapso da cultura classicista alemã". ${ }^{19}$

O nexo explícito entre a pesquisa radical da linguagem artística e o experimentalismo radical em política surge no final da seção. Benjamin afirma aí que os contemporâneos diferem dos barrocos porque, em vez de manter um vínculo com o poder central, a geração expressionista "quando não é hostil ao Estado, revolucionária, caracteriza-se pela falta de qualquer ideia de Estado". ${ }^{20} \mathrm{O}$ expressionismo parece oscilar, portanto, entre a mística e a política, servindo de espelho às principais inquietações do pensamento benjaminiano nesse momento.$^{21}$

Pode-se compreender facilmente por que Benjamin discorre de modo tão discreto sobre a politização da arte de vanguarda. Origem do Trauerspiel alemão é, como se sabe, uma tese de livre-docência (Habilitation). Outros textos da mesma época, como o célebre "Zur Kritik der Gewalt", ${ }^{22}$ que Benjamin cita várias vezes ao longo da tese, mostram que ele estava preocupado justamente com a relação entre religião, poder, Estado, revolução e violência. Scholem relata sobre as discussões de Benjamin com Ernst Bloch e Hugo Ball, ${ }^{23}$ que certamente deviam girar em torno da relação entre arte, religião e política. Deve-se levar em conta também o fato de que a tese foi escrita não muito tempo depois da eclosão do movimento espartarquista em Berlim (1919) e da efêmera Räterepublik ("República dos Conselhos”) na Baviera (1918-1919). Pode-se dizer, em síntese, que uma das características mais marcantes dessa época foi a tendência a pensar a cultura como continuação da política por outros meios. ${ }^{24}$

Essa seção do "Prefácio" contém, portanto, todo um diagnóstico político-cultural. A crise do clacissismo alemão, no período final da "década expressionista", coincide com o início do colapso da República cujo nome de batismo ("Weimar") pretendia significar um retorno a uma Alemanha pré-moderna, isto é, ao tempo em que os ideais do iluminismo e do classicismo ainda não haviam sido testados pela realidade concreta da Revolução Industrial. Essa discussão não diz respeito, porém, apenas ao cenário conturbado da literatura e da política. No mundo menos visível das discussões filosóficas, Benjamin vê também uma outra forma de colapso: após o fim da Grande Guerra, no momento máximo da difusão das ideias expressionistas, Benjamin diagnostica (e promove) o fim da filosofia como ciência sistemática. Ele não segue, porém, o caminho aberto pelo expressionismo. A expressão subjetiva não lhe parece ser suficiente, se se pretende fazer uma crítica do pensamento totalizante da epistemologia moderna. Percebendo o risco de uma retomada do egocentrismo romântico, Benjamin aposta na linguagem sóbria e prosaica do ensaio. Pois, longe de buscar o absoluto na expressão, Benjamin tem em vista o que não tem expressão 
(das Ausdruckslose). ${ }^{25}$ Esta, porém, é outra história. E os trabalhos exemplares de Jeanne Marie Gagnebin podem contá-la, sem trair o seu mistério.

Abstract: This article aims to demonstrate that the section "Baroque and Expressionism" in the "Erkenntniskritische Vorrede" includes more than a comparison between two artistic styles. When discussing "der Zusammenbruch des deutschen klassizistischen Kultur" Benjamin seems to intend, in fact, to make a sketch of the relations between art, politics and science in the the turbulent early years of the Weimar Republic.

Keywords: expressionism; epistemology; politics.

\section{Referências}

ANZ, Thomas. Literatur des Expressionismus. Stuttgart; Weimar: Metzler, 2010.

BENJAMIN, Walter. Briefe. Frankfurt/M.: Suhrkamp, 2010.

BENJAMIN, Walter. Gesammelte Schriften I. Frankfurt/M.: Suhrkamp, 1991.

BENJAMIN, Walter. Gesammelte Schriften II. Frankfurt/M.: Suhrkamp, 1991.

CAVAlCANTI, Cláudia (org.). Poesia expressionista alemã: uma antologia. São Paulo: Estação Liberdade, 2000.

DILTHEY, Wilhelm. "Das Verstehen anderer Personen und ihrer Lebensäusserungen”. In: Gesammelte Schriften, v. 7. Stuttgart: B. G. Teubner, 1961.

FREITAS, Romero. "Estranhamento ou empatia? Notas sobre o problema do conhecimento histórico em Walter Benjamin". ArteFilosofia, Ouro Preto, n. 1, maio de 2006, p. 94-102.

GAGNEBIN, Jeanne Marie. “A Propósito do Conceito de Crítica em Walter Benjamin”. Discurso, São Paulo, n. 13, $2^{\circ}$ semestre de 1980, p. 219-230.

GAGNEBIN, Jeanne Marie. “A questão do 'Eros' na obra de Walter Benjamin”. ArteFilosofia, Ouro Preto, n. 4, janeiro de 2008, p. 39-44.

GAGNEBIN, Jeanne Marie. "Críticas Estéticas e Políticas da kátharsis entendida como Identificação".In: DUARTE, Rodrigo; FIGUEIREDO, Virgínia; FREITAS, Verlaine; KANKUSSU, Imaculada (orgs). Kátharsis: reflexões de um conceito estético. Belo Horizonte: C/Arte, 2002.

GAGNEBIN, Jeanne Marie. "Da escrita filosófica em Walter Benjamin”. In: SELIGMANN-SILVA, Márcio (org). Leituras de Walter Benjamin. São Paulo: Annablume, 1999. 
GAGNEBIN, Jeanne Marie. "Documentos da cultura/Documentos da barbárie". In: Ide, São Paulo, v. 31, n. 148, junho de 2008, p. 70-82.

GAGNEBIN, Jeanne Marie. "Histoire, Memóire et Oubli chez Walter Benjamin". Revue de Métaphysique et de Morale, Paris, ano 99, n. 3, p. 365-389,

GAGNEBIN, Jeanne Marie. "Políticas da estética" (Entrevista concedida a Romero Freitas e Luciano Gatti). ArteFilosofia, Ouro Preto, n. 6, abril de 2009, p. 106-122.

GAGNEBIN, Jeanne Marie. História e Narrativa em Walter Benjamin. São Paulo: Perspectiva, 1994.

GAGNEBIN, Jeanne Marie. Lembrar Escrever Esquecer. São Paulo: Editora 34, 2006.

GAGNEBIN, Jeanne Marie. Sete Lições sobre Linguagem, Memória e História. Rio de Janeiro: Imago, 1997.

GILMAN, Stuart. A Berlim de Bertolt Brecht. Rio de Janeiro: José Olímpio, 1996.

HEGEL, Georg Wilhelm Friedrich. Cursos de estética I. São Paulo: EDUSP, 2001.

LÖWITH, Karl. Meaning in history. Chicago: The University of Chicago Press, 1949.

MOELLER, Magdalena (org.). Meisterstücke. Die schönsten Neuerwerbungen des Brücke-Museums. München: Hiermer, 2013.

SCHOLEM, Gershom. Walter Benjamin. Die Geschichte einer Freundschaft. Frankfurt/M.: Suhrkamp, 1975.

\section{Notas}

${ }^{1}$ Jeanne Marie Gagnebin foi, no Brasil, quem mais trabalhou no sentido de nos livrar desses dois erros. Cf. Referências.

${ }^{2}$ Benjamin refere-se também ao expressionismo no projeto da revista Angelus Novus (cf. BENJAMIN. Gesammelte Schriften II, p. 242 e 244), no ensaio sobre Karl Kraus (ibidem, p. 351 e 364), no ensaio sobre Kafka (ibidem, p. 419) e no texto "Judeus na cultura alemã" (ibidem, p. 823). Significativa para a relação entre Benjamin e o expressionismo é uma observação das memórias de Gershom Scholem, segundo a qual Benjamin via na literatura expressionista criação forçada, inautenticidade e até mesmo blefe (cf. SCHOLEM. Walter Benjamin, p. 169). Também são valiosas as observações de uma carta de Benjamin a Ernst Schoen (24.06.1919), nas quais Benjamin caracteriza o expressionismo como arte que se limita a documentar ou descrever com 
precisão processos interiores do espírito - no que se percebe implícita uma censura à ausência de potencial crítico dessa forma de arte (cf. BENJAMIN. Briefe, p. 214). Na tese de livre-docência, essas críticas não têm espaço, pois trata-se de apresentar o expressionismo como sintoma.

${ }^{3}$ BENJAMIN. Gesammelte Schriften I, p. 234.

${ }^{4}$ BENJAMIN. Gesammelte Schriften I, p. 234.

${ }^{5}$ BENJAMIN. Gesammelte Schriften I, p. 235-236.

${ }^{6}$ Analogias entre o barroco e a arte moderna podem nos parecer óbvias. No Brasil, isso se deve certamente ao trabalho precursor de Haroldo de Campos e Afonso Ávila (dentre outros). Na República de Weimar, porém, a teoria da arte hegemônica na universidade ainda é o classicismo romantizado de Goethe e Schiller, reformulado e difundido ao longo do século XIX por autores como Rosenkranz, Vischer e Volkelt. Não é coincidência, certamente, o fato de que este último aparece no livro sobre o Trauerspiel como representante de uma estética acadêmica a ser superada.

${ }^{7}$ Dilthey emprega o método da revivência, por exemplo, em um texto de 1910: Das Verstehen anderer Personen und ihrer Lebensäusserungen ("A compreensão de outras pessoas e de suas manifestações vitais"). Cf. Referências.

${ }^{8}$ Cf. GAGNEBIN. Da escrita filosófica em Walter Benjamin.

${ }^{9}$ Sobre a crítica benjaminiana da empatia, cf. GAGNEBIN. Críticas estéticas e políticas da kátharsis entendida como identificação; FREITAS. Estranhamento ou empatia? Notas sobre o problema do conhecimento histórico em Walter Benjamin.

${ }^{10}$ Cf. BENJAMIN. Gesammelte Schriften I, p. 233-234.

${ }^{11} \mathrm{Cf}$. LÖWITH. Meaning in History.

${ }^{12}$ BENJAMIN. Gesammelte Schriften I, p. 235.

${ }^{13}$ BENJAMIN. Gesammelte Schriften I, p. 235.

${ }^{14}$ BENJAMIN. Gesammelte Schriften I, p. 235.

${ }^{15} \mathrm{Cf}$. ANZ. Literatur des Expressionismus.

${ }^{16}$ In: CAVALCANTI. Poesia expressionista alemã, p. 119.

17 Tome-se, como exemplo, uma carta de Ernest Ludwig Kirchner ao colecionador Gustav Schiefler, na qual o pintor se refere à sua identificação com as prostitutas (Kokotten) que as suas telas representavam. Cf. MOELLER. Meisterstücke. Die schönsten Neuerwerbungen des Brücke-Museums, p. 40.

${ }^{18}$ HEGEL. Cursos de estética I, p. 126.

${ }^{19}$ BENJAMIN. Gesammelte Schriften I, p. 235.

${ }^{20}$ BENJAMIN. Gesammelte Schriften I, p. 236.

${ }^{21}$ Cf. GAGNEBIN. História e narração em Walter Benjamin.

${ }^{22}$ Cf. BENJAMIN. Gesammelte Schriften II, p. 179-203.

${ }^{23}$ Cf. SCHOLEM. Walter Benjamin. Die Geschichte einer Freundschaft, p. 92.

${ }^{24}$ Cf. GILMAN. A Berlim de Bertolt Brecht, p. 18.

${ }^{25}$ Cf. BENJAMIN. Gesammelte Schriften I, p. 181, 182 e 194. 